\title{
PELATIHAN PENGGUNAAN APLIKASI E-LEARNING BERBASIS WEB DI SD IT IMAM ASY-SYAFI'I PEKANBARU
}

\author{
Febrizal Alfarasy Syam ${ }^{1}$, Yuvi Darmayunata ${ }^{2}$, Lucky Lhaura Van FC \\ 1,2,3 Universitas Lancang Kuning, Pekanbaru, Indonesia \\ Jalan Yos Sudarso KM. 08 Rumbai, Pekanbaru-Riau, (0761) 53108 -53236 \\ email.febrizal@unilak.ac.id, yuvidarmayunita@unilak.ac.id, lucky@unilak.ac.id
}

\begin{abstract}
Abstrak: Pengabdian ini dilakukan di SD IT Asy-Syafi'i Pekanbaru, berupa pelatihan untuk guru-guru di lingkungan sekolah terhadap pengelolaan aplikasi e-Learning. Saat ini dalam proses pembelajaran siswa, SDIT Imam Asy-Syafi'i menggunakan sistem daring dengan tools media sosial seperti whatsapp sehingga menyulitkan guru-guru dalam penyampaian materi dan pengumpulan tugas karena guru-guru harus memeriksa satu per satu pesan yang masuk ke whatsapp nya. Pihak sekolah juga tidak menggunakan media video conference seperti zoom, dikarenakan akan memakan banyak kuota siswanya, dan jika kuota siswa habis saat video conference maka siswa akan ketinggalan pelajaran. Oleh karena itu diperlukan media pembelajaran yang dapat mengatasi hal tersebut yaitu sebuah aplikasi e-Learning berbasis web. Dimana, pada aplikasi e-learning berbasis web yang dibuat oleh tim pengabdian akan menyesuaikan kebutuhan SDIT Imam Asy-Syafi'i. Berdasarkan hasil kuesioner, pemahaman guru-guru terhadap penggunaan aplikasi e-learning sudah baik yaitu $85,7 \%$ menyatakan paham tentang pengelolaan aplikasi e-learning.
\end{abstract}

Kata Kunci: e-learning, SDIT Imam Asy-Syafi'i, pelatihan

\begin{abstract}
This service was carried out at SD IT Asy-Syafi'i Pekanbaru, in the form of training for teachers in the school environment in managing e-Learning applications. Currently in the student learning process, SDIT Imam Asy-Syafi'i uses an online system with social media tools such as WhatsApp, making it difficult for teachers to deliver material and collect assignments because teachers have to check one by one the messages that go to their WhatsApp. The school also does not use video conferencing media such as zoom, because it will consume a lot of student quota, and if the student quota runs out during the video conference, students will miss lessons. Therefore we need learning media that can overcome this, namely a web-based e-Learning application. Where, the web-based e-learning application made by the community service team will match the needs of SDIT Imam Asy-Syafi'i. Based on the results of the questionnaire, the teachers' understanding of the use of e-learning applications was good, namely $85.7 \%$ stated that they understood the management of e-learning applications.
\end{abstract}

Keywords: e-learning, SDIT Imam Asy-Syafi', training

\section{Pendahuluan}

Proses belajar (learning) menggunakan media atau bantuan peralatan elektronik diharapkan dapat meningkatkan efektifitas dan efisiensi pembelajaran, konsep tersebut dikenal dengan sebutan e-learning. Dalam aplikasinya, media pembelajaran e-learning dapat disajikan berupa media offline maupun online (Zyainuri, Z., \& Marpanaji, E., 2012). Saat ini konsep e-Learning sudah banyak diterima oleh masyarakat dunia, terutama pada saat terjadinya pandemi covid-19, terbukti dengan maraknya implementasi e-Learning di lembaga pendidikan (sekolah, training dan universitas). Pengguna E-Learning menunutut budaya self-learning, dimana seseorang memotivasi diri sendiri agar mau belajar. Media pembelajaran berbasis teknologi atau dalam hal ini disebut juga dengan e learning merupakan sebuah penerapan teknologi yang digunakan oleh guru atau pendidik yang 
sesuai saat ini. E-learning merupakan sebuah implementasi gabungan dari antara media internet dengan model pembelajaran sesuai dengan kasus yang dihadapi (Somantri, O., Apriliani, D., Muhamad, A. W., \& Nishom, M., 2019)

SDIT Imam Asy-Syafi'i adalah lembaga pendidikan dasar di bawah naungan Yayasan Wakaf Al Ubudiyah Pekanbaru. Berdiri pada tahun 2000/2001 dengan nama SD Islam Terpadu Imam Asy Syafi'i berdasarkan rekomendasi dari Kepala Dinas Dikpora Kota Pekanbaru Nomor/Tanggal: 3446/2003/420, 25 Juni 2003. dengan nomor statistik sekolah 10406008045 dan Nomor Pokok Statistik Nasional 10404381. Saat ini dalam proses pembelajaran siswa, SDIT Imam Asy-Syafi'i menggunakan sistem daring dengan tools media sosial seperti whatsapp. Pihak sekolah tidak menggunakan media video conference seperti zoom, dikarenakan akan memakan banyak kuota siswanya, dan jika kuota siswa habis saat video conference maka siswa akan ketinggalan pelajaran. Kemudian dalam pengumpulan tugas menggunakan media sosial juga merepotkan bagi guru, karena mereka harus memeriksa satu per satu pesan yang masuk ke whatsapp nya sehingga hal tersebut cukup rumit. Oleh karena itu diperlukan media pembelajaran yang dapat mengatasi hal tersebut yaitu sebuah aplikasi e-Learning berbasis web.

Pada aplikasi e-Learning berbasis web yang dibuat oleh tim pengabdian menyesuaikan kebutuhan SDIT Imam Asy-Syafi'i yaitu apalikasi e-Learning yang ada dapat memasukan materi pembelajaran berupa soft file (pdf, ppt, doc) dan video dari youtube yang dapat dilihat dari website e-Learning tanpa harus membuka youtube agar iklan-iklan yang tidak bagus yang ada di youtube tidak terlihat oleh siswanya. Kemudian guru-guru juga dapat langsung membuat soal tugas dan siswa dapat langsung menjawabnya di aplikasi tersebut. Terkait hal diatas maka kami sebagai tim IbM mengangkat topik di atas untuk pengabdian pada skim APBF sebagai jalan keluar ataupun solusi terhadap permasalahan yang dihadapi oleh SD IT Imam Asy-Syafi'i melalui kegiatan pendampingan serta pelatihan khusus guru-guru tentang aplikasi e-learning berbasis web, agar mampu memberikan kontribusi kepada SD IT Imam Asy -Syafi'i dalam menghasilkan pelayanan yang prima dan terstuktur serta terdata didalam sistem komputerisasi.

Program PKM ini akan difokuskan pada guru-guru mata pelajaran yang ada di SD IT Imam Asy-Syafi'i. Program PKM ini akan dibimbing langsung oleh tim pengusul program pengabdian. Program PKM ini bertujuan dapat menghasilkan pelayanan informasi yang berkualitas baik dengan memanfaatkan aplikasi tersebut. Sehingga guru dan siswa dapat terbantu dalam proses belajar mengajar secara online.

\section{Metode}

Metode seminar dan tatap muka diberikan saat pemberian materi dengan menggunakan slide persentasi dan handout materi. Pada awal pertemuan para guru akan diberikan praktek langsung tentang pemahaman system kerja dari aplikasi e-learning. Kemudian para guru akan mempraktekkan langsung penggunaan dan melakukan kelola aplikasi yang telah berjalan. Metode evaluasi pencapaian target dilakukan pada awal dan akhir kegiatan. Hal ini untuk mengetahui tingkat pengetahuan peserta dan menerima masukan untuk perbaikan pada kegiatan-kegiatan berikutnya. Secara rinci kegiatan pengabdian yang akan dilakukan sebagai berikut :

1. Kegiatan perkenalan

2. Sosialisasi, Pengenalan terhadap aplikasi e-learning berbasis web

3. Pendalaman materi pelatihan

4. Melakukan tanya jawab

5. Praktek langsung 
Kegiatan ini menggunakan bebarapa perangkat pendukung di antaranya adalah :

1. Perangkat komputer / laptop

2. Aplikasi E-Learning

3. Projector

4. Smartphone.

\section{Hasil dan Pembahasan}

Pada pelaksanaan kegiatan pelatihan e-learning di SDIT Imam Asy-Syafi'i, pertama tim memberikan pemahaman kepada guru-guru peserta pelatihan tentang konsep e-learning. Pada kesempatan ini yang menyampaikan materi adalah bapak Yuvi Darmayunata, ST., M.Kom. Dalam prakteknya e-learning memerlukan bantuan teknologi. Karena itu dikenal istilah : computer based learning (CBL) yaitu pembelajaran yang sepenuhnya menggunakan komputer; dan computer assisted learning (CAL) yaitu pembelajaran yang menggunakan alat bantu utama komputer. Teknologi pembelajaran terus berkembang. Namun pada prinsipnya teknologi tersebut dapat dikelompokkan menjadi dua, yaitu: Technology based learning dan Technology based web-learning. Technology based learning ini pada prinsipnya terdiri dari Audio Information Technologies (radio, audio tape, voice mail telephone) dan Video Information Technologies (video tape, video text, video messaging). Sedangkan technology based web-learning pada dasarnya adalah Data Information Technologies (bulletin board, Internet, e-mail, telecollaboration). Dalam pelaksanaan pembelajaran sehari-hari, yang sering dijumpai adalah kombinasi dari teknologi yang dituliskan di atas (audio/data, video/data, audio/video). Teknologi ini juga sering di pakai pada pendidikan jarak jauh (distance education), dimasudkan agar komunikasi antara murid dan guru bisa terjadi dengan keunggulan teknologi e-learning ini (Suyanto, A. H., 2005).

E-Learning merupakan sebuah inovasi yang mempunyai kontribusi sangat besar terhadap perubahan proses pembelajaran, dimana proses belajar tidak lagi hanya mendengarkan uraian materi dari guru tetapi siswa juga melakukan aktivitas lain seperti mengamati, melakukan, mendemonstrasikan dan lain-lain. (Aminoto, 2014). E-learning merupakan suatu sistem pembelajaran yang efektif dan dapat digunakan dimana saja dan kapan saja tanpa terikat waktu dan tanpa harus bertatap muka. Elearning berisi materi pelajaran yang disampaikan oleh pengajar kepada siswa dan siswa dapat mendownloadnya dengan format PDF dan Document, melihat teman satu kelas, melihat mata pelajaran dan mengerjakan tugas atau quis. Materi pelajaran dan tugas atau kuis yang ada di dalam sistem e-learning dapat disesuaikan dengan kelas yang diduduki (Sihotang, H. T., 2017). Sistem E-Learning yang dikembangkan merupakan sistem pendidikan virtual berbasis web yang mempunyai tujuan utama untuk membantu proses kegiatan belajar mengajar. Sehingga melalui E-Learning, proses belajar mengajar dapat dilakukan dengan cepat dan mudah serta dapat meningkatkan efisiensi dan efektifitas waktu dan biaya (Susanti, E., \& Sholeh, M., 2008).

Setelah dilakukan pemaparan tentang konsep e-learning, kemudian tim pengabdian langsung mengajarkan praktek penggunaan aplikasi e-learning yang sudah disiapkan oleh tim pengabdian. Berikut gambar situasi saat proses pelatihan berlangsung 

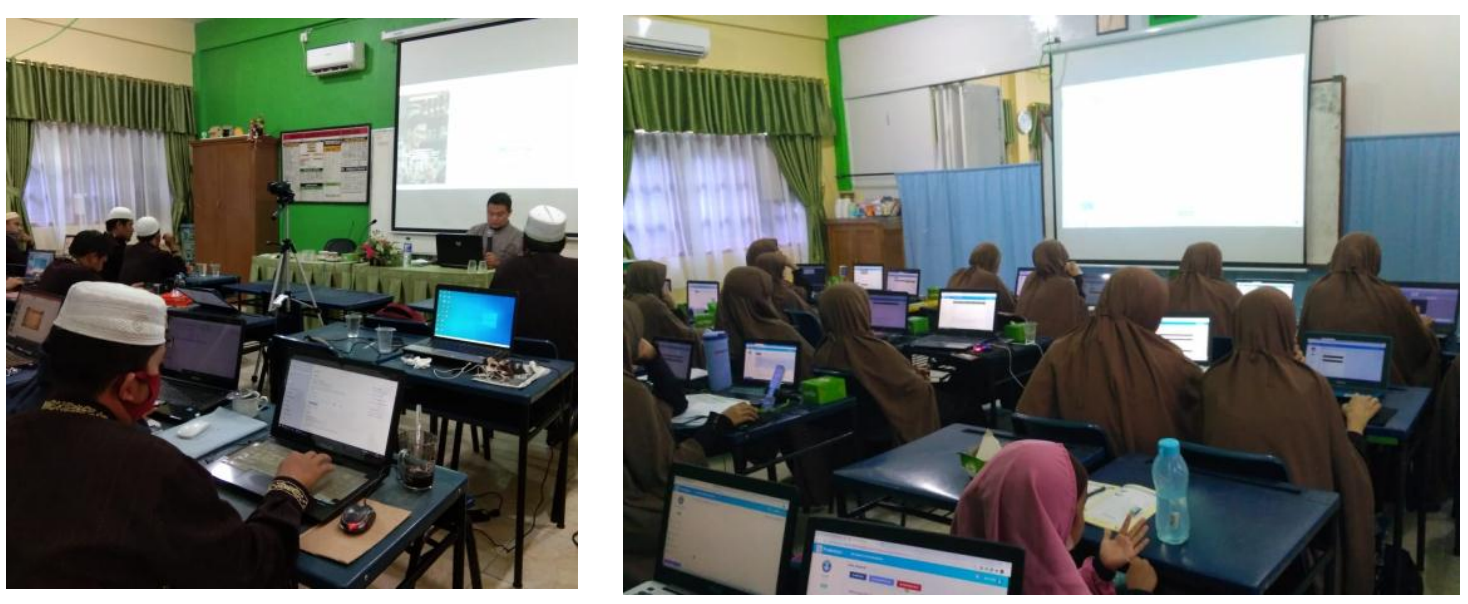

Gambar 1. Situasi Pelatihan E-Learning

Berikut gambar aplikasi e-learning yang disiapkan oleh tim pengabdian masyarakat kami :
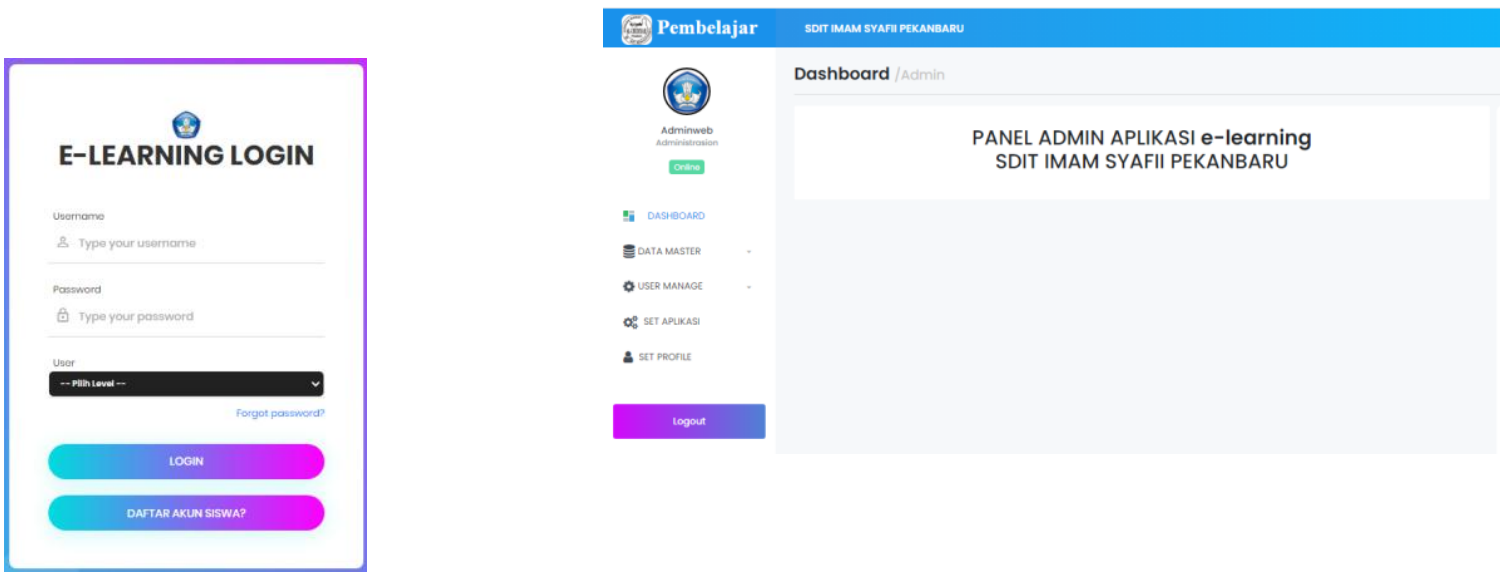

Gambar 2. Tampilan aplikasi e-learning SDIT Imam Asy-Syafi'i

Dari 30 peserta yang mengisi kuesioner evaluasi pelaksanaan kegiatan, didapatkan data bahwa berdasarkan pertanyaan terkait pemahaman peserta maka diperoleh jawaban dari peserta yaitu 85,7 \% peserta menjawab "Sudah Paham" dan 14,3\% peserta menjawab "Belum Paham". Hasil selengkapnya ini dapat dilihat pada Gambar 3. 


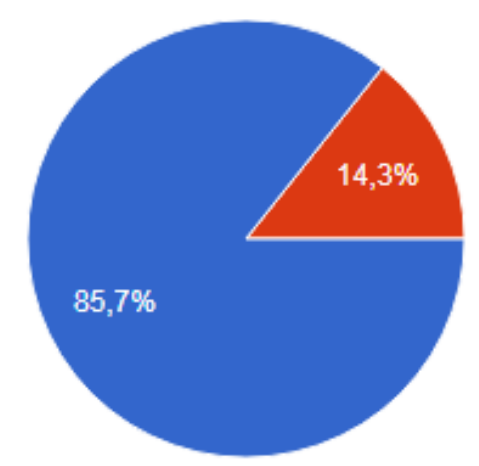

Gambar 3. Hasil Kuesioner Evaluasi Pemahaman Peserta

\section{Kesimpulan}

Berdasarkan pelaksanaan kegiatan pengabdian masyarakat ini dapat diambil kesimpulan bahwa dengan adanya Aplikasi e-learning dapat membantu siswa belajar tanpa terikat waktu mata pelajaran, mengisi waktu luangnya dengan belajar dan pengajar dapat mengajarkan siswanya tanpa terikat waktu mata pelajaran. Berdasarkan hasil kuesioner, pemahaman guru terhadap penggunaan aplikasi e-learning sudah baik yaitu $85,7 \%$ menyatakan paham tentang pengelolaan aplikasi e-learning. Berdasarkan pengamatan tim pengabdian, guru-guru sangat antusias mengikuti pelatihan yang diberikan. Kemudian kami mengucapkan terima kasih kepada bapak Sarwani, S.Ag. selaku kepala sekolah SDIT Imam Asy-Syafi'i yang telah bersedia menerima tim pengabdian kami dengan baik, kemudian juga kepada guru-guru SDIT Imam Asy-Syafi'i yang telah mengikuti pelatihan dengan baik. Dan juga kepada pihak fakultas ilmu komputer universitas lancang kuning yang telah mendanai kegiatan pengabdian kepada masyarakat yang telah kami lakukan.

\section{Daftar Pustaka}

Aminoto, T. (2014). Penerapan media e-learning berbasis schoology untuk meningkatkan aktivitas dan hasil belajar materi usaha dan energi di kelas xi sma n 10 kota jambi. Sainmatika: Jurnal Sains dan Matematika Universitas Jambi, 8(1), 221167.

Susanti, E., \& Sholeh, M. (2008). Rancang Bangun Aplikasi E-Learning. Jurnal Teknologi, 1(1), 53-57.

Sihotang, H. T. (2017). Pembuatan Aplikasi E-Learning Pada SMK Swasta Pariwisata Imelda. Jurnal Mantik Penusa, 1(2).

Suyanto, A. H. (2005). Mengenal E-learning. Universitas Gadjah Mada.[On-Line]. Tersedia: http: www. asep-hs. web. ugm. ac. id.

Somantri, O., Apriliani, D., Muhamad, A. W., \& Nishom, M. (2019). Pembangunan Media Pembelajaran Berbasis E-Learning Di SMA NU Ma'Arif Jatinegara Tegal. CARADDE: Jurnal Pengabdian Kepada Masyarakat, 1(2), 189-194.

Zyainuri, Z., \& Marpanaji, E. (2012). Penerapan e-learning moodle untuk pembelajran siswa yang melaksanakan prakerin. Jurnal Pendidikan Vokasi, 2(3). 